\title{
Addition of the $\alpha 2$-Antagonist Yohimbine to Fluoxetine: Effects on Rate of Antidepressant Response
}

\author{
Gerard Sanacora*,', Robert M Berman',4, Angela Cappiello', Dan A Oren', Akira Kugaya', Nianjun Liu', \\ Ralitza Gueorguieva ${ }^{2}$, Donna Fasula' and Dennis S Charney ${ }^{3}$ \\ 'Department of Psychiatry, Yale University School of Medicine, New Haven, CT, USA; '² Department of Epidemiology and Public Health, Yale \\ University School of Medicine, New Haven, CT, USA; ${ }^{3}$ National Institute of Mental Health, Bethesda, MD, USA
}

\begin{abstract}
Electrophysiological studies suggest that $\alpha 2$-adrenoceptors profoundly affect monoaminergic neurotransmission by enhancing noradrenergic tone and serotonergic firing rates. Recent reports suggest that $\alpha 2$-antagonism may hasten and improve the response to antidepressant medications. To test this hypothesis, a randomized double-blind controlled trial was undertaken to determine if the combination of an $\alpha 2$-antagonist (yohimbine) with a selective serotonin reuptake agent (SSRI) (fluoxetine) results in more rapid onset of antidepressant action than an SSRI agent alone. In all, 50 subjects with a DSM-IV diagnosis of major depressive disorder confirmed by SCID interview were randomly assigned to receive either fluoxetine $20 \mathrm{mg}$ plus placebo (F/P) or fluxetine $20 \mathrm{mg}$ plus a titrated dose of yohimbine $(F / Y)$. The yohimbine dose was titrated based on blood pressure changes over the treatment period, in a blind-preserving manner. Hamilton depression scale ratings (HDRS) and clinical global impression (CGI) ratings were obtained weekly over a period of 6 weeks. The rate of achieving categorical positive responses was significantly more rapid in the F/Y group compared to the F/P group using both the HDRS and the CGI scales as outcome measures in a survival analysis using a log-rank test $\left(\chi^{2}(1)=5.86, p=0.016\right.$ and $\chi^{2}(I)=5.29, p=0.021$, respectively). At the last observed visit, 18 (69\%) of the $26 \mathrm{~F} / \mathrm{Y}$ subjects met the response criteria for CGI compared to 10 (42\%) of 24 F/P subjects. Using the HDRS criteria, 17 (65\%) of $26 \mathrm{~F} / \mathrm{Y}$ subject vs 10 (42\%) of $24 \mathrm{~F} / \mathrm{P}$ subjects were responders. The addition of the $\alpha 2$-antagonist yohimbine to fluoxetine appears to hasten the antidepressant response. There is also a trend suggesting an increased percentage of responders to the combined treatment at the end of the 6-week trial.

Neuropsychopharmacology (2004) 29, I | 66-I I7I, advance online publication, 10 March 2004; doi: I 0. I038/sj.npp. I 3004 I 8
\end{abstract}

Keywords: major depression; mood disorders; treatment; $\alpha 2$-adrenergic receptor

\section{INTRODUCTION}

Enhancement of serotonergic function remains a dominant hypothesis regarding the proximal mechanism of selective serotonin reuptake inhibitor (SSRI) antidepressant action (Charney, 1998; Stahl, 1998). Opposed to the serotonergic enhancing effects of the SSRIs, activation of several inhibitory receptors including the $\alpha 2$-adrenergic auto- and heteroreceptors are known to decrease 5-HT transmission.

Previous Presentations: Portions of this study were previously presented at 57th meeting of The Society of Biological Psychiatry, Philadelphia PA, May 2002 and the 2002 American College of Neuropsychopharmacolgy meeting, San Juan, PR, December 2002.

* Correspondence: Dr G Sanacora, Clinical Neuroscience Research Unit, Abraham Ribicoff Research Facilities, Connecticut Mental Health Center, 34 Park St., New Haven, CT, USA, Tel: + I 203974 7535; Fax: + I 203974 7662, E-mail: gerard.sanacora@yale.edu

${ }^{4}$ Dr Robert M Berman is currently employed by Bristol Myers Squibb Company.

Received 27 June 2003; revised 01 December 2003; accepted 06 February 2004

Online publication: 8 January 2004 at http://www.acnp.org/citations/ Npp0 I080403284/default.pdf $\alpha 2$-heteroreceptors located on presynaptic serotonergic terminals are tonically activated by endogenous noradrenaline (NE) (Mongeau et al, 1993; Feuerstein et al, 1993), and release of serotonin is reduced when $\alpha 2$-adrenoreceptors are stimulated (Starke and Montel, 1973; Frankhuyzena and Mulder, 1980). In addition, inhibitory $\alpha 2$-autoreceptors found on noradrenergic (NA) neurons in the locus coeruleus act to decrease firing of these neurons and thus decrease serotonergic transmission by reducing activation of stimulatory $\alpha 1$-receptors located on the 5 -HT cell bodies in the raphe nucleus (Baraban and Aghajanian, 1980; Svensson et al, 1975). Systemic administration of $\alpha 2$-antagonists has been shown to enhance serotonergic neurotransmission via direct inhibition of the $\alpha 2$-heteroceptors located on the serotonergic nerve terminals and indirect stimulation of $\alpha 1$-receptors via inhibition of $\alpha 2$-autoreceptors (Freedman and Aghajanian, 1984; Hopwood and Stamford, 2001; Haddjeri et al, 1996).

Considering the inhibitory effects of the $\alpha 2$-adrenergic receptor on serotonergic function, it is hypothesized that the addition of an $\alpha 2$-antagonist to an SSRI agent may result in enhanced postsynaptic serotonergic transmission. Consistent with this hypothesis (Besson et al, 2000), 
demonstrated that the coadministration of an SSRI and mirtazapine (an agent with $\alpha 2$-antagonist activity) shortens the delay in enhancing the tonic activation of the postsynaptic $5-\mathrm{HT}_{1 \mathrm{~A}}$ receptor. Based on the postulated role of enhanced serotonergic neurotransmission in the mechanism of SSRI antidepressant action, it is proposed that the addition of an $\alpha 2$-antagonist may produce a more rapid and/or enhanced antidepressant effect. Several preliminary clinical studies appear to support this premise by demonstrating effective augmentation of SSRI medications with 22-antagonist properties (Cappiello et al, 1995; Carpenter et al, 2002), and reporting rapid rates of clinical response following combination treatments with SSRIs and $\alpha 2$ antagonists (Dam et al, 1998). To further investigate this hypothesis, we investigated the effectiveness of combining yohimbine with the SSRI fluoxetine in hastening and improving the antidepressant response, using a randomized placebo-controlled double-blind study design.

\section{PATIENTS AND METHODS}

\section{Subjects and Treatments}

Subjects were recruited through newspaper advertisements indicating free treatment for major depression. A total of 50 medication-free outpatient subjects (not receiving an FDA approved antidepressant medication for at least 2 weeks prior to enrollment in the study), between the ages of 18-65 years, meeting the DSM-IV criteria for unipolar major depression without psychotic features participated in the study. All diagnoses were confirmed by a SCID interview (First et al, 2001), and all subjects had initial 25-item Hamilton Rating Scale (Mazure et al, 1986) (HDRS) for Depression of $>21$. After completing a written informed consent process as approved by the Yale University and Connecticut VA institutional review boards, subjects were randomly assigned to receive one of two treatments: fluoxetine $20 \mathrm{mg}$ QD plus placebo TID $(n=24)$ or fluoxetine $20 \mathrm{mg}$ QD plus yohimbine TID $(n=26)$. Yohimbine $(5.4 \mathrm{mg}$ tabs; Watson Laboratories) and placebo were encapsulated identically. Yohimbine was titrated from one capsule TID up to a maximum of two tablets TID, in increments of one tablet per week based on maintenance of a diastolic blood pressure less than $90 \mathrm{~mm} / \mathrm{Hg}$ and less than a $10 \mathrm{~mm} / \mathrm{Hg}$ increase over the previous measurement. If a subject's blood pressure remained $>140 / 100 \mathrm{~mm} / \mathrm{Hg}$ or $\mathrm{HR} 100 \mathrm{bpm}$ the dose was cut by $5 \mathrm{mg}$; if it remained elevated after 1 week the subject was discharged from the study. Blood pressure was followed weekly by a third-party monitor who was not involved in the treatment or ratings of the subject. This monitor directly contacted the research pharmacist to determine medication dosing. To assure blinding of the subjects' clinicians and raters, the pharmacist yoked the number of placebo tablets administered to the number of yohimbine tablets administered to a randomly chosen yohimbine-treated subject. The introduction of additional psychotropic medications was not allowed during the 6-week assessment period.

\section{Assessments}

Subjects were seen weekly for assessments of mood and side effects. Rating assessments included the 25-item HDRS
(Mazure et al, 1986), Clinical Global Impressions Scale for severity (CGI) (Guy, 1986), Hamilton Anxiety Rating Scale (HARS) (Hamilton, 1969), and the Arizona Sexual Experience scale (ASEX) (this was performed on the last 27 subjects, as it was added later in the study) (McGahuey et al, 2000).

\section{Statistical Analysis}

The main outcome of interest was time to antidepressant response. This was examined using a survival analysis, with the 'survival time' defined as the time when a subject met the $a$ priori determined response criteria. The criterion for HDRS was defined as a score of $\leqslant 10$, reflecting a measure consistent with remission. For CGI, the criterion was defined as a score of $\leqslant 2$ (borderline ill, no functional impairment). Subjects were considered responders at the time they met response criteria for the first time. In the case of dropout before becoming responder, the subject was censored after the last time-point that data was collected. The survival analyses were performed using PROC LIFETEST in SAS 8.2. $\chi^{2}$ tests were used to compare percent responders at end point based on the HDRS and on the CGI criteria explained above. End point data was analyzed using the last observation carried forward method. Change in HDRS ratings was also analyzed using a mixed models approach (in SAS PROC MIXED) with treatment, time, and treatment by time effects. Change in CGI ratings were also analyzed using a GEE cumulative-logit model for ordinal data (in SAS PROC GENMOD) with treatment, time, and treatment by time effects.

As secondary analyses, HARS and ASEX (in a subset of subjects) ratings were analyzed using mixed models with treatment, time, treatment by time effects, and baseline as covariates. The data were checked for normality by the Kolmogorov-Smirnov tests. The models were fitted in SAS PROC MIXED with AR(1) variance-covariance structure. All statistical tests were two-sided and performed at 0.05 significance level.

\section{RESULTS}

The demographics and clinical characteristics are presented in Table 1. There was no significant difference between the two groups of subjects in terms of baseline severity of depression or anxiety, duration of current episode, number

Table I Demographic Characteristics of Treatment Groups

\begin{tabular}{lcc}
\hline & $\begin{array}{c}\text { Fluoxetine and } \\
\text { Yohimbine } \\
(\mathbf{N}=\mathbf{2 6})\end{array}$ & Fluoxetine \\
& $(\mathbf{N}=\mathbf{2 4 )}$ \\
\hline Age [mean \pm SD] & $46.97 \pm 10.08$ & $40.50 \pm 8.45$ \\
Sex (M/F) & $42.3 \% / 57.7 \%$ & $33.3 \% / 66.7 \%$ \\
Weight (lbs.) [mean \pm SD] & $168.54 \pm 51.03$ & $182.67 \pm 57.64$ \\
Number of past MDE [mean \pm SD] & $2 \pm 2$ & $2 \pm 1.8$ \\
$\begin{array}{l}\text { Duration of symptoms (weeks) [mean } \\
\pm \text { SD] }\end{array}$ & $64.12 \pm 41.09$ & $50.65 \pm 37.79$ \\
\hline
\end{tabular}

MDE, major depressive episodes. 
of previous episodes, age, weight, sexual dysfunction, or gender composition. The combined sample was composed of $38 \%$ males and $62 \%$ females with mean $( \pm S D)$ age of $43.9 \pm 9.8$ years. The mean baseline HDRS was $30 \pm 6$. The majority of subjects (70\%) had prior major depressive episodes, and $48 \%$ of the sample had received a previous antidepressant trial at some point. Only four of the subjects had a history of psychiatric hospitalization, and four subjects had a history of suicide attempt or gesture. The average duration of current episode was $58 \pm 40$ weeks.

Seven subjects from the F/Y group (27\%) discontinued the study before the end of week 6 , due to emergent hypertension (4), urinary retention (1), and loss to followup (2). Three of the F/Y subjects discontinued the study after achieving response criteria. Five subjects from the $\mathrm{F} / \mathrm{P}$ group $(21 \%)$ discontinued prior to the end of week 6, due to worsening of depressive symptoms (2), rash (1), acute onset of Lyme disease (1), and loss to follow-up (1). None of the F/P subjects achieved response criteria prior to discontinuing the study. In all, 15 of the 19 subjects in the F/Y group who completed the study tolerated the titration up to $10.8 \mathrm{mg}$ TID, with the mean dose being $27.6 \pm 4.8 \mathrm{mg}$ at the end of the trial. Yohimbine dose increases were limited in four subjects due to increased blood pressure (2), tremulousness (1), and lightheadedness (1).

\section{Antidepressant Response}

The subjects in the $F / Y$ group more rapidly met the predetermined HDRS response criterion (final HDRS 10) than did the F/P group using a Log rank test $\left[\chi^{2}(1)=5.86\right.$, $p=0.016]$. Figure 1a depicts the Kaplan-Meier estimates of the survival curve for the HDRS criterion. The subjects in the $\mathrm{F} / \mathrm{Y}$ group also more rapidly met the response CGI criterion using the Log $\operatorname{rank}$ test $\left[\chi^{2}(1)=5.29, p=0.021\right]$. Figure $1 \mathrm{~b}$ depicts the Kaplan-Meier estimates for the CGI criterion. Although the mean HDRS scores (Table 2) and CGI scores were numerically lower in the F/Y group at every time point in the study, there was not a significant time by treatment interaction for the change from baseline in either measure $[\mathrm{F}(5,197)=0.67, p=0.65]$ and $\left[\chi^{2} \quad(5)=8.08\right.$, $p=0.15$ ] respectively (Figure 2 ). There was, however, a significant time effect for $\operatorname{HDRS}[\mathrm{F}(5,197)=22.81$, $p<0.0001]$ and for CGI $\left[\chi^{2}(5)=49.01, p<0.0001\right]$, indicating that both treatment groups improved over the course of the study. In all, $17(65 \%)$ of 26 subjects in the F/Y group, and $10(42 \%)$ of 24 subjects in the control group met the HDRS response criterion $\left[\chi^{2}(1)=2.83\right.$, $p=0.09$ ] at the time of the last observed visit. The $F / Y$ group had significantly more responders at the last observed visit, according to the CGI criterion, with 18 $(69 \%)$ of 26 compared to $10(42 \%)$ of $24\left[\chi^{2}(1)=3.85\right.$, $p=0.05]$.

\section{Anxiety Symptoms}

Neither the time by treatment interaction $[\mathrm{F}(6,44.4)=1.18$, $p=0.33]$ or main treatment effect $[\mathrm{F}(1,46.4)=0.59$, $p=0.45]$ were significant, thus suggesting no significant difference between the mean response of the F/Y group and the $\mathrm{F} / \mathrm{P}$ group over time. Both groups showed a reduction in a HDRS Total Score

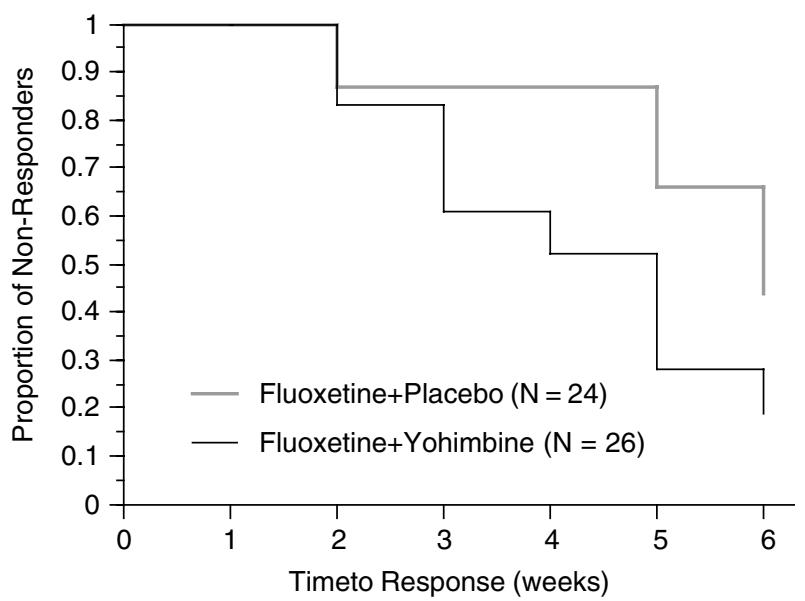

b CGI Severity

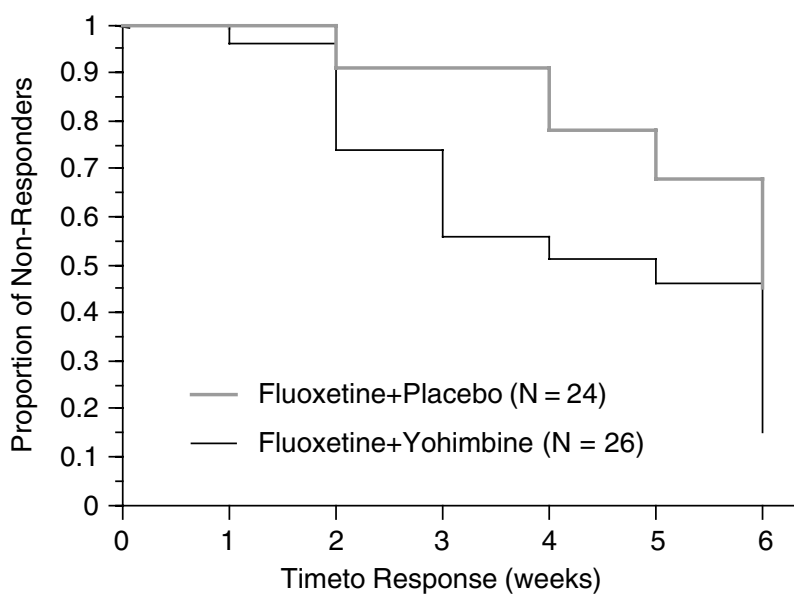

Figure I Survival curves for response among patients with major depression treated with either fluoxetine + placebo or fluoxetine + yohimbine. (a) Kaplan-Meier estimates of the survival curve for subjects not meeting the HDRS criterion for response (HDRS $\leqslant 10)$. Groups differed significantly by log-rank test ( $p=0.016$ ). (b) Kaplan-Meier estimates of the survival curve for subjects not meeting the CGl criterion for response $(C G l \leqslant 2)$. Groups differed significantly by log-rank test $(p=0.021)$.

Table 2 Hamilton Depression Rating Scores (Mean \pm SD, range) and Group Sizes Over the Course of the Study

\begin{tabular}{lclll}
\hline & \multicolumn{2}{c}{ Fluoxetine and Yohimbine } & \multicolumn{2}{c}{ Fluoxetine and Placebo } \\
\hline Baseline & $29.27 \pm 6.02,20-41$ & $(N=26)$ & $31.08 \pm 6.30,22-43$ & $(N=24)$ \\
Week I & $23.27 \pm 5.86,12-35$ & $(N=26)$ & $26.13 \pm 6.92,12-42$ & $(N=24)$ \\
Week 2 & $18.43 \pm 7.91,6-34$ & $(N=23)$ & $20.91 \pm 7.62,6-38$ & $(N=22)$ \\
Week 3 & $15.57 \pm 8.85,5-34$ & $(N=21)$ & $19.82 \pm 7.91,3-37$ & $(N=22)$ \\
Week 4 & $14.35 \pm 8.47,2-34$ & $(N=20)$ & $18.61 \pm 8.62,1-38$ & $(N=23)$ \\
Week 5 & $10.58 \pm 5.98,1-26$ & $(N=19)$ & $14.25 \pm 8.35,0-33$ & $(N=20)$ \\
Week 6 & $8.89 \pm 6.58,0-25$ & $(N=19)$ & $11.68 \pm 6.55,0-23$ & $(N=19)$ \\
\hline
\end{tabular}

HARS scores following treatment (Table 3 ), and there was a significant time effect $(\mathrm{F}(6,44.4)=10.73, p<0.0001)$, indicating that there was significant improvement with time for both the groups. 

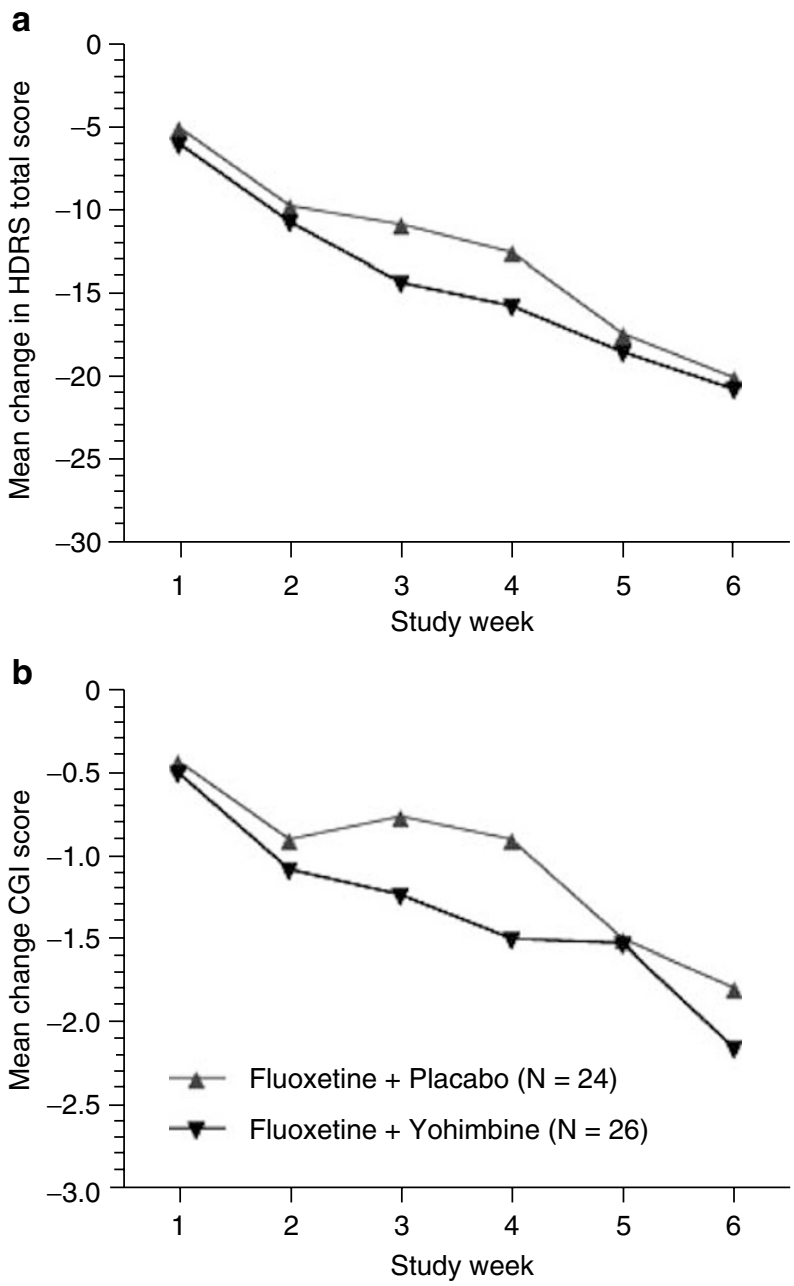

Figure 2 Mean changes in Hamilton depression rating scores ${ }^{\mathrm{a}}$ and clinical global impression ratings ${ }^{\mathrm{b}}$ over the study period.

Table 3 Baseline and Post-Treatment Measures

\begin{tabular}{|c|c|c|}
\hline & $\begin{array}{c}\text { Fluoxetine and } \\
\text { Yohimbine } \\
(N=26)^{*}\end{array}$ & $\begin{array}{c}\text { Fluoxetine } \\
(\mathrm{N}=24)^{*}\end{array}$ \\
\hline \multicolumn{3}{|l|}{ Baseline measurements } \\
\hline $\mathrm{HDRS}[$ mean $\pm \mathrm{SD}$, range] & $29.27 \pm 6.02,20-41$ & $31.08 \pm 6.30,22-43$ \\
\hline $\mathrm{CGI}[$ mean $\pm \mathrm{SD}$, range $]$ & $4.08 \pm 0.56,3-5$ & $4.29 \pm 0.69,3-6$ \\
\hline ASEX $[$ mean $\pm S D$, range $]$ & $17.92 \pm 6.01,10-29$ & $16.40 \pm 7.03,6-29$ \\
\hline $\mathrm{HARS}[$ mean $\pm \mathrm{SD}$, range $]$ & $13.65 \pm 4.78,7-26$ & $15.0 \pm 5.44,6-24$ \\
\hline \multicolumn{3}{|l|}{ Last observed measurements } \\
\hline HDRS [mean $\pm S D$, range $]$ & $11.65 \pm 8.95,0-34$ & $15.13 \pm 9.25,0-33$ \\
\hline $\mathrm{CGl}[$ mean $\pm \mathrm{SD}$, range $]$ & $2.35 \pm 1.16,1-15$ & $2.88 \pm 1.26,1-5$ \\
\hline ASEX $[$ mean $\pm S D$, range $]$ & $16.33 \pm 5.85,9-27$ & $16.40 \pm 6.43,9-30$ \\
\hline HARS [mean $\pm \mathrm{SD}$, range $]$ & $7.65 \pm 4.9||-19$, & $7.7 I \pm 4.79,0-22$ \\
\hline
\end{tabular}

*ASEX fluoxetine and yohimbine $(N=12)$, fluoxetine, and placebo $(N=10)$. HDRS, Hamilton depression rating scores; CGl, clinical global impression scores; ASEX, Arizona sexual experience scale; HARS, Hamilton anxiety rating scores.

\section{Sexual Dysfunction Results}

Since the ASEX was added to the rating battery at a later time, we were only able to collect the ASEX ratings on 27 subjects (15 F/Y and $12 \mathrm{~F} / \mathrm{P})$ (Table 3). In this limited sample we did not find the time by treatment interaction to be significant $[\mathrm{F}(5,68.9)=0.57, p=0.72]$. This suggests no significant difference between the mean ASEX response of the $\mathrm{F} / \mathrm{Y}$ group and the mean response of the F/P group over time. There was a trend, however, showing lower ASEX scores in the F/Y group by weeks 5 and 6 of the trial.

\section{DISCUSSION}

The main findings of this study are consistent with the hypothesis postulating that coadministration of $\alpha 2$-antagonists can hasten the antidepressant effects of SSRI medications. Subjects receiving fluoxetine in combination with yohimbine appear to respond more rapidly than those receiving fluoxetine alone do, showing earlier categorical responses on both HAM-D and CGI scales. The results are similar to those of a previous study that demonstrated a statistically significant greater reduction of depressive symptoms shortly after the initiation of treatment with fluoxetine combined with mianserin (an agent with $\alpha 2$ antagonist properties) compared to fluoxetine alone (Dam et al, 1998). However, unlike the previous study that demonstrated significantly greater improvement at the end of the first week of treatment with mianserin, we did not see major differences between the two conditions until the end of the third week of treatment. This raises the possibility of a minimal yohimbine dose threshold that is reached only after a 3-week period of dose escalation. However, it may also suggest that the enhanced antidepressant effect is not fully accounted for by the acute effects of $\alpha 2$-antagonism. Interestingly, two recent reviews examining the onset time of antidepressant action for mirtazapine, a compound with antagonist properties at both $\alpha 2$-adrenergic auto- and heteroreceptors, suggest that it may also be associated with an earlier onset of response (Quitkin et al, 2001; Nierenberg, 2001).

The end point analyses also suggest a trend for combined therapy subjects reaching response criteria in greater numbers at the 6-week period, supporting the idea that $\alpha 2$-antagonists lead to improved antidepressant efficacy. This is consistent with a study by (Carpenter et al, 2002), in which treatment refractory depressed subjects, most of whom were receiving SSRI medications, demonstrated a categorical response rate of $64 \%$ after 4 -weeks of mirtazapine augmentation compared to a $20 \%$ categorical response rate with placebo addition.

The findings of the study are tempered, however, by the fact that we did not demonstrate a significant main effect of treatment or a treatment by time interaction in the mixed models analyses examining mean changes in HDRS and CGI scores. This may be accounted for by the fact that the primary parameter of interest, time to response, is calculated individually for each patient in the survival analysis technique rather than from group means, thus providing a more accurate measure of the parameter (Thase, 2001). The fact that the dropout mechanism was informative and different in the two groups (three of the F/Y subjects dropped out after obtaining a response, while none of the $\mathrm{F} / \mathrm{P}$ dropouts achieved a response prior to termination) may also contribute to this apparent 
contradiction. However, the discrepancy could also be the result of an artifact caused by the choice of a defined response criterion (HDRS $\leqslant 10$ ) and a baseline HDRS that is numerically but not statistically lower in the F/Y group.

In general, our results are consistent with the previously proposed hypothesis that concomitant administration of $\alpha 2$-antagonists and SSRI medications may lead to more rapid rates of antidepressant effects by shortening the delay in obtaining tonic activation of the postsynaptic $5-\mathrm{HT}_{1 \mathrm{~A}}$ receptors (Besson et al, 2000). It is important to state, however, that yohimbine is not a highly selective $\alpha 2$ antagonist since it also binds to 5-HT2, and dopamine D2 receptors (Krystal et al, 1992). Beyond increasing postsynaptic serotonergic activation, the effect may also be related to enhanced activation of the NA system via blockade of the inhibitory $\alpha 2$-receptor. Thus, the dual activation of the serotonergic and NA systems simultaneously may contribute to findings. It does not appear likely, however, that increasing NA transmission alone is responsible for the effect since a previous study, combining yohimbine with the NA selective agent desipramine, failed to show any benefit over desipramine alone in a sample of treatment refractory subjects (Charney et al, 1986). Lastly, an additional caveat in interpreting the findings of this study is drawn from the fact that serum concentrations of fluoxetine were not measured in the subjects. Therefore, we cannot rule out the possibility that yohimbine is having a pharmacokinetic effect that results in altered metabolism of fluoxetine. However, this does not seem to be a likely explanation considering the lack of clear evidence to support a significant dose-response effect with fluoxetine at doses greater than $20 \mathrm{mg}$ in the treatment of major depression.

Interestingly, we did not see any worsening of anxiety symptoms in this study. $\alpha 2$-antagonists have been shown to induce panic attacks in susceptible individuals (Krystal et al, 1992); however, we did not see any significant increase in panic attacks or anxiety ratings on the HARS. In fact, there was a significant improvement in HARS over the 6-week course that appeared independent of whether or not yohimbine was administered. Yohimbine has also been reported to ameliorate antidepressant-associated sexual dysfunction (Hollander and McCarley, 1992; Price and Grunhaus, 1990), although a recent placebo-controlled trial did not support this claim (Michelson et al, 2002). Our preliminary findings from this study do not show a clear effect of yohimbine on sexual function but suggest a possible trend for improved function in the later weeks of the trial in the subjects randomized to combination therapy.

In conclusion, the addition of the $\alpha 2$-antagonist yohimbine appears to hasten and possibly improve the antidepressant response rates to the SSRI agent fluoxetine. This finding is consistent with the hypothesis that concomitant administration of $\alpha 2$-antagonists and SSRI medications may lead to more rapid rates of antidepressant effects. While the findings are of significant interest in relationship to our understanding of the underlying neurobiology associated with antidepressant action, they do not clearly support the clinical use of yohimbine as a clinical agent. Several of the subjects in this study developed hypertension with the combination and we were unable to clearly show any benefit of the combination at the end of the 6-week trial. Additional studies concerning the clinical usefulness of the combination are required.

\section{ACKNOWLEDGEMENTS}

This work was supported by NIMH K08 MH01715-01 (GS), and the Mental Health Clinical Research Center at Yale MH30929-21 (GS, DSC), VA Research Enhancement Award Program (GS, AK). We would also like to thank Lisa Roach and Matthew Wachen for their assistance.

\section{REFERENCES}

Baraban JM, Aghajanian GK (1980). Suppression of firing activity of 5-HT neurons in the dorsal raphe by alpha-adrenoceptor antagonists. Neuropharmacology 19: 355-363.

Besson A, Haddjeri N, Blier P, de Montigny C (2000). Effects of the co-administration of mirtazapine and paroxetine on serotonergic neurotransmission in the rat brain. Eur Neuropsychopharmacol 10: 177-188.

Carpenter LL, Yasmin S, Price LH (2002). A double-blind, placebocontrolled study of antidepressant augmentation with mirtazapine. Biol Psychiatry 51: 183-188.

Cappiello A, McDougle CJ, Malison RT, Heninger GR, Price LH (1995). Yohimbine augmentation of fluvoxamine in refractory depression: a single-blind study. Biol Psychiatry 38: 765-767.

Charney DS (1998). Monoamine dysfunction and the pathophysiology and treatment of depression. J Clin Psychiatry 59: 11-14.

Charney DS, Price LH, Heninger GR (1986). Desipramineyohimbine combination treatment of refractory depression. Implications for the beta-adrenergic receptor hypothesis of antidepressant action. Arch Gen Psychiatry 43: 1155-1161.

Dam J, Ryde L, Svejso J, Lauge N, Lauritsen B, Bech P (1998). Morning fluoxetine plus evening mianserin versus morning fluoxetine plus evening placebo in the acute treatment of major depression. Pharmacopsychiatry 31: 48-54.

Feuerstein TJ, Mutschler A, Lupp A, Van Velthoven V, Schlicker E, Gothert M (1993). Endogenous noradrenaline activates alpha 2adrenoceptors on serotonergic nerve endings in human and rat neocortex. J Neurochem 61: 474-480.

First M, Spitzer R, Gibbon M, Williams J (2001). Structured Clinical Interview for DSM-IV-TR Axis I Disorders, Research Version, Non-patient Edition. (SCID-I/NP). Biometrics Research, New York State Psychiatric Institute: New York.

Frankhuyzen AL, Mulder AH (1980). Noradrenaline inhibits depolarization-induced $3 \mathrm{H}$-serotonin release from slices of rat hippocampus. Eur J Pharmacol 63: 179-182.

Freedman JE, Aghajanian GK (1984). Idazoxan (RX 781094) selectively antagonizes alpha 2-adrenoceptors on rat central neurons. Eur J Pharmacol 105: 265-272.

Guy W (1976). ECDEU Assessment Manual. National Institute of Mental Health, Rockville, MD.

Haddjeri N, Blier P, de Montigny C (1996). Effect of the alpha-2 adrenoceptor antagonist mirtazapine on the 5-hydroxytryptamine system in the rat brain. J Pharmacol Exp Ther 277: 861-871.

Hamilton M ed. (1969). Diagnosis and Rating of Anxiety, Br J Psychiatry Spec Publ.

Hollander E, McCarley A (1992). Yohimbine treatment of sexual side effects induced by serotonin reuptake blockers. J Clin Psychiatry 53: 207-209.

Hopwood SE, Stamford JA (2001). Noradrenergic modulation of serotonin release in rat dorsal and median raphe nuclei via alpha(1) and alpha(2A) adrenoceptors. Neuropharmacology 41: 433-442. 
Krystal JH, McDougle CJ, Woods SW, Price LH, Heninger GR, Charney DS (1992). Dose-response relationship for oral idazoxan effects in healthy human subjects: comparison with oral yohimbine. Psychopharmacology 108: 313-319.

Mazure C, Nelson JC, Price LH (1986). Reliability and validity of the symptoms of major depressive illness. Arch Gen Psychiatry 43: 451-456.

McGahuey CA, Gelenberg AJ, Laukes CA, Moreno FA, Delgado PL, McKnight KM et al (2000). The Arizona Sexual Experience Scale (ASEX): reliability and validity. J Sex Marital Ther 26: 25-40.

Michelson D, Kociban K, Tamura R, Morrison MF (2002). Mirtazapine, yohimbine or olanzapine augmentation therapy for serotonin reuptake-associated female sexual dysfunction: a randomized, placebo controlled trial. J Psychiatric Res 36: 147-152.

Mongeau R, Blier P, de Montigny C (1993). In vivo electrophysiological evidence for tonic activation by endogenous noradrenaline of alpha 2-adrenoceptors on 5-hydroxytryptamine terminals in the rat hippocampus. Naunyn-Schmiedebergs Arch Pharmacol 347: 266-272.
Nierenberg AA (2001). Do some antidepressants work faster than others? J Clin Psychiatry 62: 22-25.

Price J, Grunhaus LJ (1990). Treatment of clomipramine-induced anorgasmia with yohimbine: a case report. J Clin Psychiatry 51: 32-33.

Quitkin FM, Taylor BP, Kremer C (2001). Does mirtazapine have a more rapid onset than SSRIs? J Clin Psychiatry 62: 358-361.

Stahl SM (1998). Mechanism of action of serotonin selective reuptake inhibitors. Serotonin receptors and pathways mediate therapeutic effects and side effects. J Affect Disord 51: 215-235.

Starke K, Montel H (1973). Involvement of alpha-receptors in clonidine-induced inhibition of transmitter release from central monoamine neurones. Neuropharmacology 12: 1073-1080.

Svensson TH, Bunney BS, Aghajanian GK. (1975). Inhibition of both noradrenergic and serotonergic neurons in brain by the alpha-adrenergic agonist clonidine. Brain Res 92: 291-306.

Thase ME (2001). Methodology to measure onset of action. J Clin Psychiatry 62: 18-21. 